\title{
Surgical Strategy for T1 Duodenal or Ampullary Carcinoma According to the Depth of Tumor Invasion
}

\author{
ATSUSHI KOHGA ${ }^{1}$, YUSUKE YAMAMOTO ${ }^{1}$, SHUSEI SANO ${ }^{1}$, TEIICHI SUGIURA ${ }^{1}$, \\ YUKIYASU OKAMURA ${ }^{1}$, TAKAAKI ITO ${ }^{1}$, RYO ASHIDA ${ }^{1}$, HIROTOSHI ISHIWATARI ${ }^{2}$, \\ HIROYUKI MATSUBAYASHI ${ }^{2}$, KEIKO SASAKI ${ }^{3}$ and KATSUHIKO UESAKA ${ }^{1}$ \\ Divisions of ${ }^{1}$ Hepato-Biliary-Pancreatic Surgery, ${ }^{2}$ Endoscopy, ${ }^{3}$ Pathology, Shizuoka Cancer Center, Shizuoka, Japan
}

\begin{abstract}
Aim: To investigate the utility of local resection (LR) for T1 duodenal carcinoma and T1 ampullary carcinoma. Patients and Methods: Between June 2002 and November 2014, a total of 64 patients with pathological T1 (pT1) ampullary carcinoma (25 patients) and pT1 duodenal carcinoma (39 patients) were treated. Of these, 33 patients underwent local resection (LR group), while the other 31 patients underwent pancreatoduodenectomy (PD group). Results: The LR group had 31 patients with pTla and 2 patients with pT1b.PD group had 18 patients with pTla and 13 patients with pT1b. One patient with pTlb duodenal carcinoma (20.0\%) and one patient with pT1b ampullary carcinoma (10.0\%) developed lymph node metastasis, while none of the patients with pTla disease developed metastases. Conclusion: LR may be considered in the patients preoperatively diagnosed with Tla duodenal carcinoma and Tla ampullary carcinoma.
\end{abstract}

Tumors of the duodenum or the ampulla of Vater represent a small portion of gastrointestinal tumors, accounting for less than $1 \%$ of all gastrointestinal malignancies (1-4). Complete resection is the only potential curative procedure for duodenal or ampullary carcinoma, and various techniques have been proposed for its management ranging from local resection (LR) to pancreatoduodenectomy (PD) (5-8). The method of resection typically depends on the depth of tumor invasion for the treatment of various gastrointestinal tract cancers $(9,10)$. In the field of duodenal and ampullary carcinomas, PD is standard treatment for advanced invasive

Correspondence to: Yusuke Yamamoto, MD, Division of HepatoBiliary-Pancreatic Surgery, Shizuoka Cancer Center, 1007, ShimoNagakubo, Sunto-Nagaizumi, Shizuoka 4118777, Japan. Tel: +81 559895222, Fax: +81 559895783, e-mail: yusu.yamamoto@scchr.jp

Key Words: Local resection, duodenal carcinoma, ampullary carcinoma. malignancies $(5,6)$. Recently, LR has been introduced as an alternative, less-invasive procedure for the treatment of early-stage duodenal and ampullary carcinomas in select patients, because PD carries a high risk of morbidity and mortality (11-13). However, its indication for the treatment for early-stage carcinoma remains unclear because duodenal or ampullary carcinoma is an uncommon disease, and the rate of lymph node metastasis, which usually depends on the depth of tumor invasion, also remains unclear. Furthermore, it is difficult to preoperatively assess the accurate depth of invasion in patients with ampullary carcinoma, in particularly whether the sphincter of Oddi is involved (14).

The aim of the present study was to review a cohort of patients with early-stage duodenal and ampullary carcinomas and identify the clinicopathological factors that indicate a possible benefit in LR by comparing the results to those of patients who underwent PD for early-stage duodenal and ampullary carcinomas.

\section{Patients and Methods}

Study population. Between June 2002 and November 2014, 76 patients with ampullary carcinoma and 70 patients with duodenal carcinoma underwent macroscopic curative resection at the Division of Hepato-Biliary-Pancreatic Surgery, Shizuoka Cancer Center. Of these patients, 25 patients had pathological T1 (pT1) ampullary carcinoma and 39 patients had pT1 duodenal carcinoma according to the TNM classification (7th edition) of the American Joint Committee on Cancer (AJCC) (12). Overall, 64 patients with pT1 ampullary and duodenal carcinomas were enrolled in this study. Of these, 31 patients underwent PD (PD group) and 33 patients underwent LR (LR group); 4 patients underwent pancreas-sparing duodenectomy, 1 patient underwent segmental resection of the duodenum, 24 patients underwent partial resection of the duodenum, and 4 patients underwent ampullectomy. Patients with benign lesions, gastrointestinal stromal tumors or neuroendocrine tumors were excluded from this study.

Imaging diagnostic modality. Among 64 patients examined, all patients underwent computed tomography (CT) and esophagogastroduodenoscopy for diagnostic purposes. Thirty-nine patients 

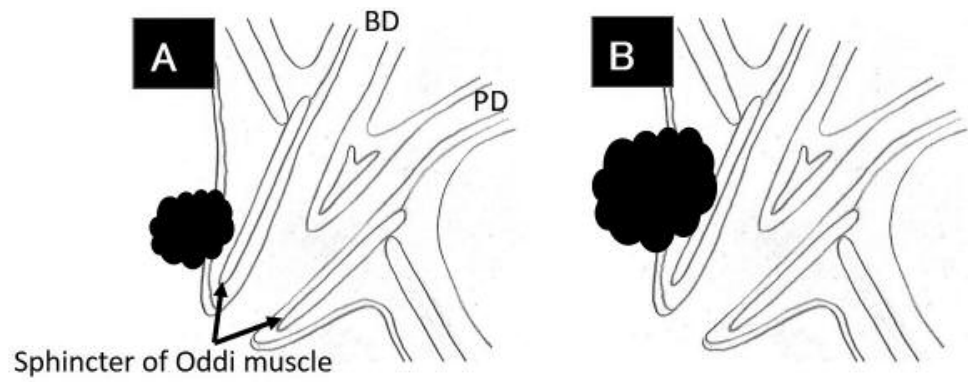

Figure 1. The T1a and T1b defined the patients with ampullary carcinoma as bellow, according to the Japanese classification for biliary tract cancers. A) Tla: invasion to only the mucosa. B) T1b: invasion to the sphincter of Oddi. BD, Bile duct; PD, pancreatic duct.

underwent preoperative endoscopic ultrasonography (EUS) and 11 patients underwent intraductal ultrasonography (IDUS) in order to diagnose the depth of tumor invasion.

Surgical strategy and surgical procedures for ampullary and duodenal carcinomas. In our institution, PD with regional lymph node dissection was routinely performed for advanced ampullary and duodenal carcinomas. For the patients with clinical T1a duodenal carcinoma, LR was planned. For the patients with clinical T1b duodenal carcinoma, PD with regional lymph node dissection was indicated. In the patients with clinical T1 ampullary carcinoma, PD was initially planned. For the patients with T1 ampullary carcinoma, the following conditions were considered to be candidates for LR: 1) the tumor was located only in the mucosa, 2) there was no apparent lymph node metastasis or distant metastasis, and 3) the tumor was small enough to be completely resected using LR. In the patients with ampullary carcinomas who underwent ampullectomy, frozen sections of the cut end of the specimen were examined. We performed PD when the examination of a frozen section revealed tumor involvement at the resection margin.

Clinicopathological findings. We reviewed the following clinicopathological findings of the patients: demographic parameters (gender and age), preoperative carcinoembryonic antigen (CEA) level and carbohydrate antigen 19-9 (CA19-9) level, pathological factors (tumor size, depth of tumor, histologic grade and lymph node metastasis), perioperative factors (operation time, blood loss, postoperative length of days, postoperative complication), and longterm outcomes (recurrence and survival).

In principle, the $\mathrm{T}$ classifications of duodenal and ampullary carcinoma (T1-T4) were defined with reference to the TNM classification (7th edition) of the American Joint Committee on Cancer (AJCC) (15). In addition, for the finer division of T1 ampullary carcinoma, we also referred to the Japanese classification for biliary tract cancers (16), and divided the T1 lesions of ampullary carcinoma into $\mathrm{T} 1 \mathrm{a}$ and $\mathrm{T} 1 \mathrm{~b}$ as follows: $\mathrm{T} 1 \mathrm{a}$, invasion to only the mucosa in both ampullary and duodenal carcinoma; T1b, invasion to the submucosa in patients with duodenal carcinoma or invasion to the sphincter of Oddi in patients with ampullary carcinoma (Figure 1A and $\mathrm{B}$ ).

Postsurgical management. Complications were classified according to the grading system of Dindo et al. (17), and grade III or further complications were considered to be significant. None of the patients received adjuvant chemotherapy, radiotherapy, or chemoradiotherapy. All patients were examined in the outpatient clinic where abdominal ultrasound, CT, and the measurement of the CEA and CA19-9 levels was performed every 3-6 months after surgery.

Statistical analysis of the surgical outcomes and clinicopathological factors. The clinicopathological factors of the patients treated using LR were compared with those treated using PD.

Pearson's Chi-square test and Fisher's exact test were used to assess nominal variables, and continuous data were compared using the Mann-Whitney $U$-test. All statistical analyses were performed using the Software Package for Social Sciences, version 11.5J for Windows 1 software program (SPSS, Chicago, IL, USA). A $p$-value of $<0.05$ was considered significant. We performed Yates' correction for calculating the $p$-value using a two-by-two contingency table.

\section{Results}

The LR group $(n=33)$ included 31 patients with pT1a lesions (4 ampullary and 27 duodenal carcinoma) and 2 patients with pT1b duodenal cancer. The PD group $(n=31)$ included 18 patients with pT1a lesions (11 ampullary and 7 duodenal carcinoma) and 13 patients with pT1b lesions (10 ampullary and 3 duodenal carcinoma). One patient with pT1b duodenal carcinoma $(20.0 \%)$ and one patient with pT1b ampullary carcinoma (10\%) developed lymph node metastasis (Table I). On the other hand, none of the patients with pT1a developed lymph node metastasis.

Five patients with pT1 ampullary carcinoma were scheduled to undergo LR. Of these patients, two were found to have positive margins according to the findings from frozen section samples. One of the patients converted to PD, while the other could not convert to PD due to old age. Four patients with pT1 ampullary carcinoma were treated by LR alone (Table II). Three patients with pT1a duodenal carcinoma $(7.7 \%)$ and one patient with pT1a ampullary carcinoma (4\%) had previous histories of familial adenomatous polyposis. 
Kohga et al: Resection for T1 Duodenal or Ampullary Carcinoma

Table I. Clinical characteristics of the patients pathologically diagnosed to have lymph node metastasis.

\begin{tabular}{|c|c|c|c|c|c|c|c|c|}
\hline Case & $\begin{array}{l}\text { Gender/ } \\
\text { Age }\end{array}$ & $\begin{array}{l}\text { Disease/ } \\
\text { Procedure }\end{array}$ & $\begin{array}{l}\text { No. of Lymph nodes } \\
\text { metastasis/dissected }\end{array}$ & $\begin{array}{l}\text { Size } \\
(\mathrm{mm})\end{array}$ & $\begin{array}{l}\text { Depth of } \\
\text { invasion }\end{array}$ & $\begin{array}{c}\text { Pathological } \\
\text { diagnosis }\end{array}$ & $\begin{array}{c}\text { DFS } \\
\text { (month) }\end{array}$ & $\begin{array}{c}\text { OS } \\
\text { (month) }\end{array}$ \\
\hline 1 & Male/57 & $\mathrm{DC} / \mathrm{PD}$ & $1 / 28$ & 55 & pT1b & Well dif. adenoca. & 62 & 62 \\
\hline 2 & Female/51 & $\mathrm{AC} / \mathrm{PD}$ & $2 / 36$ & 15 & pT1b & Mod. dif. adenoca. & $4 *$ & 11 \\
\hline
\end{tabular}

DC, Duodenal carcinoma; AC, ampullary carcinoma; PD, pancreatoduodenectomy; Well dif. adenoca., Well differentiated adenocarcinoma; Mod. dif. adenoca., moderately differentiated adenocarcinoma; DFS, disease free survival; OS, overall survival. *Recurrence was occurred in intraabdominal lymph nodes and liver 4 months after operation.

Table II. Our cases intend to perform local resection for ampullary carcinoma.

\begin{tabular}{|c|c|c|c|c|c|c|c|c|}
\hline Case & $\begin{array}{l}\text { Gender/ } \\
\text { Age }\end{array}$ & Procedure & $\begin{array}{c}\text { Operation } \\
\text { time }(\mathrm{min}) / \\
\text { Blood loss }(\mathrm{g})\end{array}$ & $\begin{array}{c}\text { Tumor size }(\mathrm{mm}) / \\
\text { Depth of } \\
\text { invasion }\end{array}$ & $\begin{array}{l}\text { Result of } \\
\text { frozen section/ } \\
\text { Curability }\end{array}$ & $\begin{array}{l}\text { Lymph node } \\
\text { dissection }\end{array}$ & $\begin{array}{c}\text { Pathological } \\
\text { diagnosis }\end{array}$ & $\begin{array}{l}\text { Observation } \\
\text { period } \\
\text { (month) }\end{array}$ \\
\hline 1 & Female/59 & Ampullectomy & $157 / 103$ & 30/T1a & $-/ \mathrm{R} 0$ & - & Well dif. adenoca. & 67 \\
\hline 2 & Male/55 & Ampullectomy $\rightarrow$ PD & $380 / 885$ & 7/T1a & Positive/R0 & present & Well dif. adenoca. & 53 \\
\hline 3 & Male/60 & Ampullectomy* & $371 / 1333$ & 20/T1a & Negative/R0 & sampling & Well dif. adenoca. & 46 \\
\hline 4 & Male/87 & Ampullectomy & $175 / 53$ & 13/T1a & Negative/R0 & - & Well dif. adenoca. & 15 \\
\hline 5 & Male/85 & Ampullectomy & $131 / 70$ & 9/T1a & Positive/R1 & - & Well dif. adenoca. & 1 \\
\hline
\end{tabular}

PD, Pancreatoduodenectomy; Well dif. adenoca., Well differentiated adenocarcinoma. *Pancreas-sparing duodenectomy was performed concurrently. All cases have no recurrence during the observation period.

Thirty-nine patients, consisting of 25 patients $(64.1 \%)$ with duodenal carcinoma and 14 patients $(56 \%)$ with ampullary carcinoma, underwent preoperative EUS; 11 patients (44\%) with ampullary carcinoma underwent IDUS. The preoperative diagnostic sensitivity, specificity, and accuracy of EUS for pT1a duodenal carcinoma were 66.6\%, $100 \%$, and $72 \%$ respectively, while those for pT1b duodenal carcinoma were $75 \%, 71.4 \%$, and $72 \%$, respectively. None of 4 patients with pT1b duodenal carcinoma was preoperatively underestimated as clinical T1a disease. On the other hand, the preoperative diagnostic sensitivity, specificity, and accuracy of EUS and/or IDUS for pT1a ampullary carcinoma were $33.3 \%, 100 \%$, and $57.8 \%$, respectively, and those for $\mathrm{pT} 1 \mathrm{~b}$ ampullary carcinoma were $28.5 \%, 66.6 \%, 52.6 \%$, respectively. None of 7 patients with pT1b ampullary carcinoma was preoperatively underestimated as clinical T1a disease.

Comparison of the clinicopathological factors and the survival between the patients treated with $L R$ and $P D$. The preoperative CEA in the PD group was significantly higher than that in the LR group ( $p=0.026$ ) (Table III). In the LR group, 4 patients $(12.1 \%)$ had a tumor located at the ampulla of Vater, and 27 patients (81.8\%) had a tumor located in the 2 nd portion of the duodenum (other than ampullary lesions). In contrast, in the PD group 21 patients $(67.7 \%)$ had a tumor located at the ampulla of Vater, while $6(19.3 \%)$ had a tumor located in the 2nd portion of the duodenum. Tumor size was comparable between both groups. $(p=0.861)$. With regard to surgical results, the operation time $(p<0.001)$ and the amount of blood loss $(p<0.001)$ in the PD group were significantly greater than those in the LR group. Regarding the short-term outcomes, the overall morbidity $(p<0.001)$ and frequency of pancreatic fistula $(p<0.001)$ in the PD group were significantly higher than those in the LR group. The length of hospital stay in the PD group was significantly longer than that in the LR group $(p<0.001)$.

There was no in-hospital mortality observed in both groups. In the PD group, one patient with pathological T1bN1 ampullary carcinoma developed recurrence through intraabdominal lymph node metastasis and liver metastasis 4 months after surgery and died 11 months after surgery. However, in the LR group, none of the patients showed recurrence during the observation period.

\section{Discussion}

The present study analyzed the surgical results of LR and PD for early-stage duodenal and ampullary carcinomas. In this 
Table III. The results of the univariate analyses between clinicopathological factors of LR and PD.

\begin{tabular}{|c|c|c|c|}
\hline & $\mathrm{LR}(\mathrm{n}=33)$ & $\operatorname{PD}(n=31)$ & $p$-Value \\
\hline Gender; Male/Female & $21 / 12$ & $21 / 10$ & 0.796 \\
\hline Age (years) (median) & $63(21-87)$ & $68(48-83)$ & 0.160 \\
\hline CEA (ng/ml) (median) & $1.6(0.5-7.1)$ & $2.7(0.7-10.4)$ & $0.026 \uparrow$ \\
\hline CA19-9 (U/ml) (median) & $4.5(2-33)$ & $7.0(1.9-383)$ & 0.405 \\
\hline Pathological result & & & $0.003 \uparrow$ \\
\hline pT1aN0 & $31(93.9 \%)$ & $18(58.0 \%)$ & \\
\hline pT1aN1 & 0 & 0 & \\
\hline pT1bNo & $2(6.0 \%)$ & $11(35.4 \%)$ & \\
\hline pT1bN1 & 0 & $2(6.4 \%)$ & \\
\hline Location of tumor & & & $<0.001 \uparrow$ \\
\hline Ampulla of Vater & $4(12.1 \%)$ & $21(67.7 \%)$ & \\
\hline 1 st portion of duodenum & $1(3.0 \%)$ & $3(9.6 \%)$ & \\
\hline 2nd portion of duodenum & $27(81.8 \%)$ & $6(19.3 \%)$ & \\
\hline 3rd portion of duodenum & $1(3.0 \%)$ & $1(3.2 \%)$ & \\
\hline 4th portion of duodenum & 0 & 0 & - \\
\hline Tumor size $(\mathrm{mm})$ & $25.4 \pm 20.6$ & $23.7 \pm 16.6$ & 0.861 \\
\hline Operation time (min) & $185 \pm 121$ & $412 \pm 124$ & $<0.001 \uparrow$ \\
\hline Blood loss (g) & $166 \pm 255$ & $957 \pm 923$ & $<0.001 \uparrow$ \\
\hline Postoperative length of stay (day) & $13.8 \pm 8.0$ & $36.4 \pm 22.3$ & $<0.001 \uparrow$ \\
\hline Lymphatic invasion or venous invasion & & & 0.561 \\
\hline Negative & 32 & 28 & \\
\hline Positive & 1 & 3 & \\
\hline Histological grade & & & 0.055 \\
\hline Well differentiated adenocarcinoma & 33 & 26 & \\
\hline Moderately differentiated adenocarcinoma & 0 & 2 & \\
\hline Papillary adenocarcinoma & 0 & 3 & \\
\hline R0 resection & $32(96.9 \%)$ & $31(100 \%)$ & $>0.999$ \\
\hline Mortality & 0 & 0 & - \\
\hline Incident rate of postoperative complication ${ }^{\#}(\%)$ & $6(18.1 \%)$ & $25(80.6 \%)$ & $<0.001 \uparrow$ \\
\hline Pancreatic fistula & 1 & 23 & $<0.001 \uparrow$ \\
\hline Bile leakage & 0 & 1 & $>0.999$ \\
\hline Delayed gastric emptying & 1 & 3 & 0.561 \\
\hline Intraabdominal abscess & 1 & 2 & 0.561 \\
\hline Others* & 3 & 3 & 0.727 \\
\hline
\end{tabular}

LR, Local resection including below; 7 ampullectomy, 1 segmental resection, 20 partial resection, 5 pancreas-sparing duodenectomy; PD, pancreatoduodenectomy. \#Complications that were regarded as grade $3 \mathrm{a}$ or more in the classification of Clavian-Dindo. $\uparrow$ Statistically significant. *Other complications include below; 1 pancreatitis, 2 intra-abdominal hemorrhage caused by pseudo aneurism, 2 anastomosis leakage, 1 acute myocardial infarction.

study, the rate of postoperative complications in the PD group was significantly higher than that in the LR group. However, there was no in-hospital mortality observed in both groups in this study. Postoperative pancreatic fistula remains a leading cause of morbidity, and the morbidity rate after PD remains high $(30-50 \%)(18-20)$. In particular, patients with non-pancreatic cancer diseases, such as duodenal or ampullary cancer are reported to have a narrower main pancreatic duct, thicker pancreatic body, and non-fibrotic pancreas; thus, these patients are at greater risks of developing pancreatic fistula (18). However, recent improvements in surgical techniques and perioperative management have reduced surgical mortality and morbidity after PD especially in high-volume centers (18).
Furthermore, other groups have even recommended PD for cases of early duodenal or ampullary cancer in order to avoid tumor recurrence after complete lymphadenectomy $(6,21)$. Only if a patient has an extremely low probability of lymph node metastases, LR may be an alternative surgical method with lower morbidity and mortality rates.

In the present study, none of the patients with pathological T1a duodenal and ampullary carcinomas developed lymph node metastases, however, one patient with pT1b duodenal carcinoma $(20.0 \%)$ and one patient with pT1b ampullary carcinoma (10\%) developed lymph node metastasis. The consensus of the best operation method for duodenal or ampullary carcinoma has not yet been established, especially in the early stage of the diseases, however, our data suggest 
Table IV. Recent reports associated with local resection for ampullary adenocarcinoma.

\begin{tabular}{|c|c|c|c|c|c|c|c|c|}
\hline Author & Year & $\begin{array}{l}\text { No. of } \\
\text { cases }\end{array}$ & $\begin{array}{l}\text { Characteristics } \\
\text { of the patients }\end{array}$ & Procedure & $\begin{array}{r}\text { Positive margin } \\
\text { (frozen section) }\end{array}$ & $\begin{array}{c}\mathrm{LN} \\
\text { dissection }\end{array}$ & $\begin{array}{l}\text { Recurrence } \\
\text { rate } \%\end{array}$ & $\begin{array}{l}\text { 3/5-year } \\
\text { OS } \%\end{array}$ \\
\hline Demetriades (24) & 2006 & 12 & $\mathrm{pT} 1,<2 \mathrm{~cm}, \mathrm{~N}^{\dagger}$ & Ampullectomy & $0 / 12(0.0 \%)$ & + & 25 & $75 / 33.3$ \\
\hline Chen (25) & 2011 & 25 & $\mathrm{pTis}$ or $\mathrm{pT} 1, \mathrm{~N} 0$ or $\mathrm{N} 1, \mathrm{M} 0$ & PSD & $6 / 31(19.3 \%)^{\#}$ & + & 20 & $72 /-$ \\
\hline Feng (11) & 2012 & 25 & $<2 \mathrm{~cm}$ & Ampullectomy & $6 / 25(24.0 \%)$ & + & 48 & $-/ 48$ \\
\hline Zhong (23) & 2013 & 17 & $*$ & Ampullectomy & - & - & 63 & $35 / 21$ \\
\hline Zhao (26) & 2014 & 34 & $\begin{array}{c}12 \text { of pT1, } 17 \text { of pT2, } 5 \text { of pT3, } \\
0.8 \sim 3.5 \mathrm{~cm} \text { (median } 2.0 \mathrm{~cm})\end{array}$ & $\begin{array}{l}\text { Transduodenal or } \\
\text { extraduodenal LR }\end{array}$ & $3 / 34(8.8 \%)$ & $5 / 34$ & 41 & $69.5 / 53.7$ \\
\hline
\end{tabular}

LN, Lymph node; OS, overall survival; PSD, pancreas-sparing duodenectomy; LR, local resection. †Well or moderately differentiated tumors. ${ }^{\# A l l}$ 25 patents who underwent PSD were negative. Another 6 patients were found to have positive margins and converted to pancreatoduodenectomy. *LR was performed because of patient's medical comorbidity or patient preference. Including two patients with pT3 lesion.

PD with lymph node dissection may be considered as the standard procedures for $\mathrm{T} 1 \mathrm{~b}$ duodenal and ampullary carcinomas to achieve curative resection.

As for early-stage duodenal carcinoma, Kato et al. suggested that LR could be considered for the patients with pT1a lesions because the patients with pT1a duodenal carcinoma did not develop lymph node metastasis (22). In the present study, none of the 34 patients with pT1a duodenal carcinoma developed lymph node metastasis, whereas 1 of the 5 patients with pT1b duodenal carcinoma developed lymph node metastasis (20\%). Moreover, the preoperative diagnostic specificity for $\mathrm{pT} 1 \mathrm{a}$ duodenal cancer was $100 \%$. Therefore, our result suggests that LR may be considered only for the patients with duodenal carcinoma preoperatively diagnosed as clinical T1a.

On the other hand, it remains controversial as to whether or not LR is an acceptable treatment for T1 lesions of early stage of ampullary carcinoma. In recent studies, several groups reported the indications of LR for ampullary carcinoma $(11,23-26)$ (Table IV). You et al. reported that none of the ampullary carcinoma patients with tumors limited to within the sphincter of Oddi developed lymph node metastasis, while 4 of 25 patients with tumors beyond the sphincter of Oddi or into the duodenal submucosa developed lymph node metastasis (27). In the present study, all the patients with pT1a ampullary carcinoma did not develop lymph node metastasis or show recurrence. On the other hand, one patient with pT1b ampullary carcinoma (10\%) developed lymph node metastasis. Thus, it is plausible that LR could be considered for pT1a ampullary carcinoma if a negative surgical margin is confirmed and if the depth can be correctly diagnosed before surgery. However, the number of patients who met these criteria was insufficient to draw any definitive conclusions.

In our study, one patient with pT1a ampullary carcinoma intending to undergo ampullectomy was converted to PD due to positive results of a frozen section examination of resection margin. Some groups have suggested that frozen section examinations of resection margin are helpful for obtaining free resection margins for the patients with ampullary cancer who underwent $\operatorname{LR}(24,28,29)$. To confirm the curability, a careful intraoperative frozen section examination may be necessary to achieve curative resection in patients who undergo LR.

Another important issue is how to accurately assess the depth of tumor invasion preoperatively. For the patients with T1 duodenal carcinoma, preoperative EUS is useful to estimate submucosal invasion $(30,31)$. On the other hand, it is difficult to accurately assess preoperatively the depth of invasion in patients with ampullary carcinoma, in particularly whether the sphincter of Oddi is involved or not (14). However, some authors recently mentioned that the performance of both EUS and IDUS examinations allowed for a high accurate diagnosis of pTis ampullary cancer (32). In the present study, preoperative EUS and IDUS showed low sensitivity $(33.3 \%)$ and high specificity (100\%) for T1a ampullary carcinoma. These results suggested that it is difficult to accurately diagnose the depth of invasion especially in patients with ampullary carcinoma, however it is worthy of attention that none of pT1b disease was preoperatively underestimated as clinical T1a disease. Preoperative EUS and IDUS have the tendency to overestimate the depth of tumor invasion to achieve high curability as much as possible. It also suggested that further improvement of the technology for evaluating the tumor invasion to the sphincter of Oddi will increase selection of LR for patients with T1a ampullary cancer.

In patients with ampullary carcinoma, some of the previous studies showed that patients who underwent LR with regional lymphadenectomy did not show preferable outcomes (Table IV). Demetriades et al. reported the results of ampullectomy with routine lymph node dissection for 12 patients with pT1, N0, well or moderately differentiated ampullary carcinoma; 3 patients $(25 \%)$ recurred, and the 5-year overall survival rate was 
$33.3 \%$ (23). In this study, only one of 25 patients (4\%) who underwent PD for pT1b, N1 ampullary carcinoma developed recurrence and died 11 months after surgery. Therefore, it is plausible that LR with regional lymphadenectomy cannot be justified in the patients with T1b ampullary cancer, which had a relatively high risk of lymph node metastasis.

In recent reports, the result of endoscopic resection for superficial duodenal carcinoma or endoscopic papillectomy for T1a ampullary carcinoma were introduced (33-35). Endoscopic resection can lead to en-bloc resection, however, a high perforation rate was reported for the treatment of duodenal tumors (36). Regarding endoscopic papillectomy, several complications such as bleeding, pancreatitis, or papillary stenosis have been reported (37).

Anatomically, the sphincter of Oddi muscle has been reported to correspond to the muscularis mucosa of other gastrointestinal organs including duodenum. Thus, invasion to the sphincter of Oddi may indicate a classification that is closer to pT1a than pT1b (27). On the other hand, overall survival in the patients with invasion beyond the sphincter of Oddi has been reported to be closer to that of $\mathrm{T} 2$ patients with invasion to the muscle wall of the duodenum proper (27). In this study, one patient with pT1b ampullary carcinoma (10\%) developed lymph node metastasis, while none of the patients with pT1a developed lymph node metastasis. Our results suggest that cases involving invasion to the sphincter of Oddi should be considered separate from pT1a.

There were some limitations associated with this study. Ampullary carcinoma has been reported to be located in both the ampulloduodenal part, which is lined by the intestinal mucosa, and in the deeper parts, which are lined by the pancreatobiliary duct mucosa (35-38). Hence, ampullary carcinoma may have two different tumor origins: the intestinal mucosa and the pancreatobiliary mucosa (38-41). Schiergens et al. advocated that the tumor biology and clinical course of pancreatobiliary-type ampullary carcinoma resemble those of pancreatic cancer and differ from intestinal-type ampullary carcinoma (42). In the present study, this difference of ampullary carcinoma was not considered and we could not investigate how the difference of tumor origin impact on the clinical outcomes. In addition, the present study was retrospective in nature and was performed in a single-center. Furthermore, the study population, in particular the number of patients with ampullary cancer who underwent LR, was small. Although previous report also suggested that T1a ampullary carcinoma did not developed lymph node metastasis (27), further study is needed to establish the feasibility of LR for T1a ampullary carcinoma.

In conclusion, it is difficult to accurately diagnose the depth of invasion especially in patients with ampullary carcinoma, however none of pT1b duodenal or ampullary carcinoma was preoperatively underestimated as clinical T1a disease. LR may be considered in patients preoperatively diagnosed with T1a duodenal carcinoma and T1a ampullary carcinoma. Intraoperative frozen-section examination will be necessary, especially for patients with ampullary carcinoma to achieve complete resection. For the patients diagnosed with clinical T1b lesions or worse, PD with lymph node dissection should be considered both in patients with duodenal carcinoma and ampullary carcinomas.

\section{References}

1 Branum GD, Pappas TN and Meyers WC: The management of tumors of the ampulla of Vater by local resection. Ann Surg 224: 621-627, 1996.

2 Howe JR, Klimstra DS, Moccia RD, Conlon KC and Brennan MF: Factors predictive of survival in ampullary carcinoma. Ann Surg 228: 87-94, 1998.

3 Hatzaras I, Palesty JA, Abir F, Sullivan P, Kozol RA, Dudrick SJ and Longo WE: Small-bowel tumors: epidemiologic and clinical characteristics of 1260 cases from the connecticut tumor registry. Arch Surg 142: 229-325, 2007.

4 Jabbour SK and Mulvihill D: Defining the role of adjuvant therapy: ampullary and duodenal adenocarcinoma. Semin Radiat Oncol 24: 85-93, 2014.

5 Kim RD, Kundhal PS, McGilvray ID, Cattral MS, Taylor B, Langer B, Grant DR, Zogopoulos G, Shah SA, Greig PD and Gallinger S: Predictors of failure after pancreaticoduodenectomy for ampullary carcinoma. J Am Coll Surg 202: 112-119, 2006.

6 Bakaeen FG, Murr MM, Sarr MG, Thompson GB, Farnell MB, Nagorney DM, Farley DR, van Heerden JA, Wiersema LM, Schleck CD and Donohue JH: What prognostic factors are important in duodenal adenocarcinoma? Arch Surg 135: 635641, 2000.

7 Liu XF, Tang K, Sun FB, Sui LL and Xu G: Partial resection of the pancreatic head and duodenum for management of carcinoma of the ampulla of vater: A case report. Anticancer Res 36: 1319-1324, 2016.

8 Papalampros A, Moris D, Petrou A, Dimitrokallis N, Karavokyros I, Schizas D, Delladetsima I, Pappas TN and Felekouras E: Non-whipple operations in the management of benign, premalignant and early cancerous duodenal lesions. Anticancer Res 37: 1443-1452, 2017.

9 Japanese Gastric Cancer Association: Japanese gastric cancer treatment guidelines 2010 (ver. 3). Gastric Cancer 14: 113-123, 2011.

10 Tanaka S, Kashida H, Saito Y, Yahagi N, Yamano H, Saito S, Hisabe T, Yao T, Watanabe M, Yoshida M, Kudo SE, Tsuruta O, Sugihara KI, Watanabe T, Saitoh Y, Igarashi M, Toyonaga T, Ajioka Y, Ichinose M, Matsui T, Sugita A, Sugano K, Fujimoto $\mathrm{K}$ and Tajiri H: JGES guidelines for colorectal endoscopic submucosal dissection/endoscopic mucosal resection. Dig Endosc 27: 417-434, 2015.

11 Feng J, Zhou X and Mao W: Prognostic analysis of carcinoma of the ampulla of Vater: pancreaticoduodenectomy versus local resection. Hippokratia 16: 23-28, 2012.

12 Kim RD, Kundhal PS, McGilvray ID, Cattral MS, Taylor B, Langer B, Grant DR, Zogopoulos G, Shah SA, Greig PD and Gallinger S: Predictors of failure after pancreaticoduodenectomy for ampullary carcinoma. J Am Coll Surg 202: 112-119, 2006.

13 Guilbaud T, Turrini O, Lemoine C, LE Treut YP, Ouaissi M, Moutardier V and Delpero JR: Venous Resection in Pancreatic 
Ductal Adenocarcinoma: Impact of Surgical Experience on Early Postoperative Courses. Anticancer Res 37: 4205-4213, 2017.

14 Yoshiyuki Matsumura and Satoshi Hirano: Surgical treatment for carcinoma of the Ampulla of Vater. JJBA 28: 833-839, 2014.

15 Wiley-Blackwell: International Union Against cancer (UICC). TNM Classification of Malignant Tumors. 7th ed. 2010, New York

16 Miyazaki M, Ohtsuka M, Miyakawa S, Nagino M, Yamamoto M, Kokudo N, Sano K, Endo I, Unno M, Chijiiwa K, Horiguchi A, Kinoshita H, Oka M, Kubota K, Sugiyama M, Uemoto S, Shimada M, Suzuki Y, Inui K, Tazuma S, Furuse J, Yanagisawa A, Nakanuma Y, Kijima $\mathrm{H}$ and Takada T: Classification of biliary tract cancers established by the Japanese Society of Hepato-Biliary-Pancreatic Surgery: 3(rd) English edition. J Hepatobiliary Pancreat Sci 22: 181-196, 2015.

17 Dindo D, Demartines N and Clavien PA: Classification of surgical complications: a new proposal with evaluation in a cohort of 6336 patients and results of a survey. Ann Surg 240: 205-213, 2004.

18 Yamamoto Y, Sakamoto Y, Nara S, Esaki M, Shimada K and Kosuge T: A preoperative predictive scoring system for postoperative pancreatic fistula after pancreaticoduodenectomy. World J Surg 35: 2747-2755, 2011.

19 Yeo CJ, Cameron JL, Sohn TA, Lillemoe KD, Pitt HA, Talamini MA, Hruban RH, Ord SE, Sauter PK, Coleman J, Zahurak ML, Grochow LB and Abrams RA: Six hundred fifty consecutive pancreaticoduodenectomies in the 1990s: pathology, complications, and outcomes. Ann Surg 226: 248-257, 1997.

20 Muscari F, Suc B, Kirzin S, Hay JM, Fourtanier G, Fingerhut A, Sastre B, Chipponi J, Fagniez PL and Radovanovic A: French Associations for Surgical Research: Risk factors for mortality and intra-abdominal complications after pancreatoduo-denectomy: multivariate analysis in 300 patients. Surgery 139: 591-598, 2006.

21 Bucher P, Gervaz P and Morel P: Long-term results of radical resection for locally advanced duodenal adenocarcinoma. Hepatogastroenterology 52: 1727-1729, 2005.

22 Kato Y, Takahashi S, Kinoshita T, Shibasaki H, Gotohda N and Konishi M: Surgical procedure depending on the depth of tumor invasion in duodenal cancer. Jpn J Clin Oncol 44: 224-231, 2014.

23 Zhong J, Palta M, Willett CG, McCall SJ, Bulusu A, Tyler DS, White RR, Uronis HE, Pappas TN and Czito BG: The role of local excision in invasive adenocarcinoma of the ampulla of Vater. J Gastrointest Oncol 4: 8-13, 2013.

24 Demetriades H, Zacharakis E, Kirou I, Pramateftakis MG, Sapidis $\mathrm{N}$, Kanellos I and Betsis D: Local excision as a treatment for tumors of ampulla of Vater. World J Surg Oncol 4: 14, 2006.

25 Chen G, Wang H, Fan Y, Zhang L, Ding J, Cai L, Xu T, Lin H and Bie P: Pancreas-sparing duodenectomy with regional lymphadenectomy for pTis and pT1 ampullary carcinoma. Surgery 151: 510-517, 2012.

26 Zhao X, Dong J, Huang X, Zhang W and Jiang K: Prognostic factors for survival of patients with ampullary carcinoma after local resection. ANZ J Surg 85: 567-571, 2015.

27 You D, Heo J, Choi S, Choi D and Jang KT: Pathologic T1 subclassification of ampullary carcinoma with perisphincteric or duodenal submucosal invasion: Is it T1b? Arch Pathol Lab Med 138: 1072-1076, 2014.

28 Yoon YS, Kim SW, Park SJ, Lee HS, Jang JY, Choi MG, Kim WH, Lee KU and Park YH: Clinicopathologic analysis of early ampullary cancers with a focus on the feasibility of ampullectomy. Ann Surg 242: 92-100, 2005.
29 de Castro SM, van Heek NT, Kuhlmann KF, Busch OR, Offerhaus GJ, van Gulik TM, Obertop H and Gouma DJ: Surgical management of neoplasms of the ampulla of Vater: local resection or pancreatoduodenectomy and prognostic factors for survival. Surgery 136: 994-1002, 2004.

30 Goda K, Kikuchi D, Yamamoto Y, Takimoto K, Kakushima N, Morita Y, Doyama H, Gotoda T, Maehata Y and Abe N: Endoscopic diagnosis of superficial non-ampullary duodenal epithelial tumors in Japan: Multicenter case series. Dig Endosc 26: 23-29, 2014.

31 Azih LC, Broussard BL, Phadnis MA, Heslin MJ, Eloubeidi MA, Varadarajulu S and Arnoletti JP: Endoscopic ultrasound evaluation in the surgical treatment of duodenal and periampullary adenomas. World J Gastroenterol 19: 511-515, 2013.

32 Okano N, Igarashi Y, Hara S, Takuma K, Kamata I, Kishimoto $\mathrm{Y}$, Mimura $\mathrm{T}$, Ito $\mathrm{K}$ and Sumino $\mathrm{Y}$ : Endosonographic preoperative evaluation for tumors of the ampulla of vater using endoscopic ultrasonography and intraductal ultrasonography. Clin Endosc 47: 174-177, 2014.

33 Seo JY, Hong SJ, Han JP, Jang HY, Myung YS, Kim C, Lee YN and Ko BM: Usefulness and safety of endoscopic treatment for nonampullary duodenal adenoma and adenocarcinoma. J Gastroenterol Hepatol 29: 1692-1698, 2014.

34 Ito K, Fujita N and Noda Y: Endoscopic diagnosis and treatment of ampullary neoplasm (with video). Dig Endoscv 23: 113-117, 2011.

35 Matsui T, Matsubayashi H, Hotta K, Sasaki K, Ito $\mathrm{H}$ and Ono $\mathrm{H}$ : A case of carcinoma in an adenoma of the duodenal minor papilla successfully treated with endoscopic mucosal resection. Endosc Int Open 4: E252-E254, 2016.

36 Yamamoto Y, Yoshizawa N, Tomida H, Fujisaki J and Igarashi M: Therapeutic outcomes of endoscopic resection for superficial non-ampullary duodenal tumor. Dig Endosc 26: 50-56, 2014.

37 De Palma GD: Endoscopic papillectomy: indications, techniques, and results. World J Gastroenterol 20: 1537-1543, 2014.

38 Fischer HP and Zhou H. Pathogenesis of carcinoma of the papilla of Vater: J Hepatobiliary Pancreat Surg 11: 301-309, 2004.

39 Kimura W, Futakawa N, Yamagata S, Wada Y, Kuroda A, Muto $\mathrm{T}$ and Esaki Y: Different clinicopathologic findings in two histologic types of carcinoma of papilla of Vater. Jpn J Cancer Res 85: 161-166, 1994.

40 Westgaard A, Tafjord S, Farstad IN, Cvancarova M, Eide TJ, Mathisen O, Clausen OP and Gladhaug IP: Pancreatobiliary versus intestinal histologic type of differentiation is an independent prognostic factor in resected periampullary adenocarcinoma. BMC Cancer 8: 170, 2008.

41 Westgaard A, Pomianowska E, Clausen OP and Gladhaug IP: Intestinal-type and pancreatobiliary-type adenocarcinomas: how does ampullary carcinoma differ from other periampullary malignancies? Ann Surg Oncol 20: 430-439, 2013.

42 Schiergens TS, Reu S, Neumann J, Renz BW, Niess H, Boeck $\mathrm{S}$, Heinemann V, Bruns CJ, Jauch KW and Kleespies A: Histomorphologic and molecular phenotypes predict gemcitabine response and overall survival in adenocarcinoma of the ampulla of Vater. Surgery 158: 151-161, 2015.

Received July 6, 2017

Revised August 3, 2017

Accepted August 8, 2017 